\title{
Erratum
}

\section{Interrelations of the Rat's Thalamic Reticular and Dorsal Lateral Geniculate Nuclei}

P. T. Hale, A. Jervie Sefton, L. A. Baur, and L. J. Cottee

Dept. of Physiology, University of Sydney, Sydney, New South Wales 2006, Australia

Exp Brain Res (1982) 45: 217-229

To comply with the author's request we are publishing below Fig. 7 which had been missing in the manuscript of the above paper due to an unfortunate mishap.

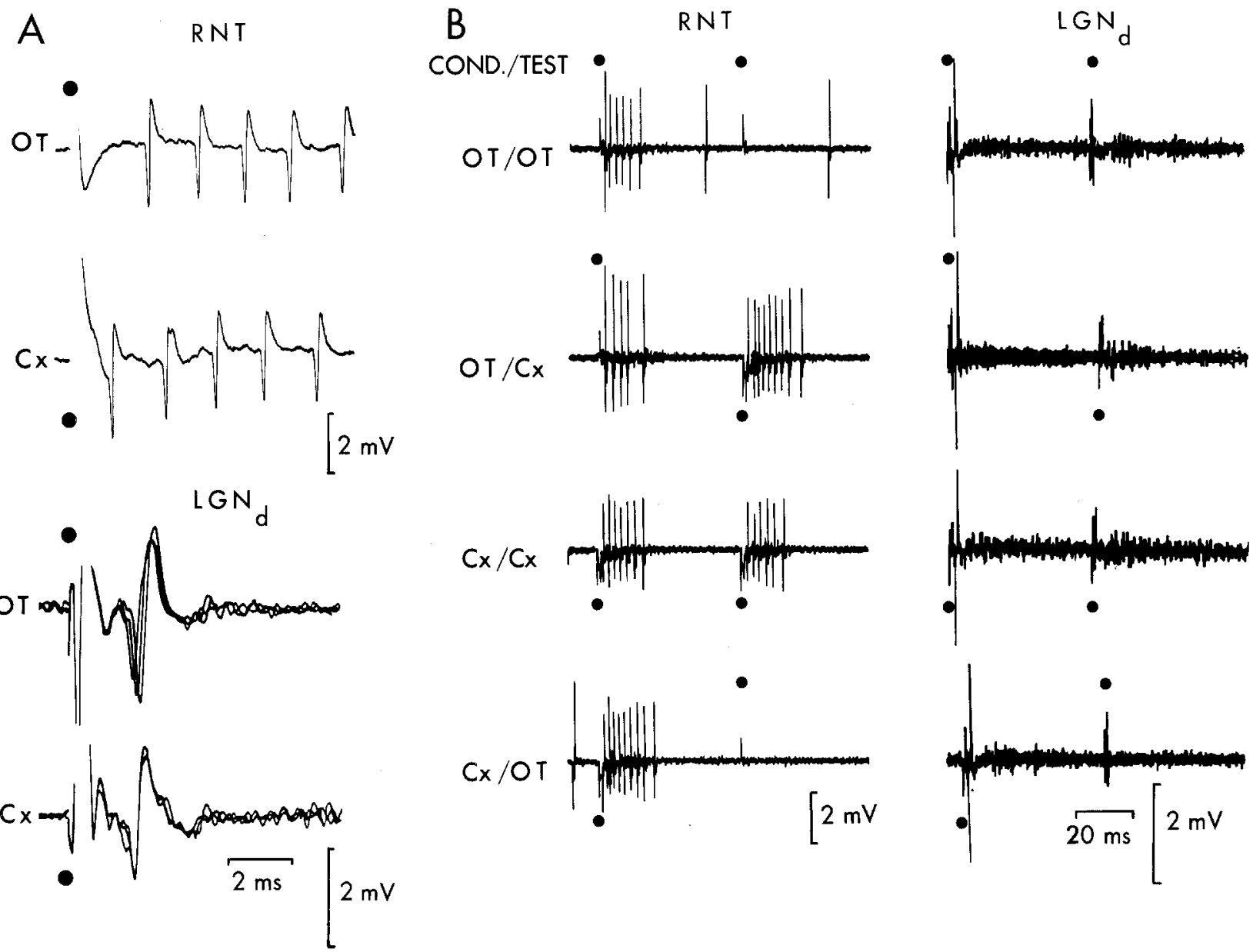

Fig. 7A, B. Records of cells in RNT and LGNd. Dot indicates stimulus in each casc. A Response of a cell in RNT to a single shock applied to optic tract and visual cortex; superimposed traces of the response of a relay cell in LGNd to a similar stimulus. B Responses of a cell in RNT and in LGN to two shocks, applicd as indicated. Note that the RNT cell responds when the second stimulus is applied to cortex, whether the first shock was applicd to cortex or to optic tract

\section{Announcement}

\section{6th European Conference on Visual Perception} Il Ciocco, Castelvecchio Pascoli, Lucca, Italy: August 28-31, 1983

The conference is intended to bring together psychophysicists and neurophysiologists interested in the study of visual perception in man and other higher vertebrates.
Deadline for abstracts: March 15, 1983. Further information: Dr. A. Fiorentini, Istituto di Neurofisiologia del CNR, Via S. Zeno, 51, I-56100 Pisa, Italy. 